\title{
THE CERN HEAVY ION ACCELERATING FACILITY
}

\author{
H. D. Haseroth, CERN, for the Lead Ion Accelerating Facility Collaboration, \\ CERN CH-1211 Geneva 23, Switzerland
}

CERN's Lead Ion Accelerating Facility has been operating successfully for its first physics run. The facility, supported financially by some member states and designed, built and installed in a collaboration with several other laboratories (not only from member states), features a completely new linac and a major up-grade of the existing CERN machines. This paper reviews the design philosophy and discusses the present performance and the first operating experience.

\section{INTRODUCTION}

The work reported here [1] is the result of a collaboration between different laboratories, namely GANIL (Caen, France), Legnaro (INFN, Italy), GSI (Darmstadt, Germany), Torino (University, Italy) and CERN (Geneva, Switzerland), supported by financial contributions from Sweden and Switzerland. and helped with software and some hardware from India (VECC, Calcutta, TIFR and BARC, Bombay), a debuncher from IAP (Frankfurt, Germany) and manpower for installation from Prague (Czech Academy of Sciences).

The scheme [2] followed the model of the successful collaboration [3,4] between GSI, LBL (Berkeley, USA) and CERN for oxygen and sulphur ion acceleration using Linac 1. This collaboration was a consequence of the acceleration of deuterons and alpha particles in the Linac (Linac 1), PSB (Proton Synchrotron Booster), PS (Proton Synchrotron) and the ISR (Intersecting Storage Rings). Deuterons were produced by the conventional duoplasmatron source as used for the protons, alpha particles by stripping a $\mathrm{He}^{1+}$ beam after the preaccelerator. $\mathrm{O}^{6+}$ beams and $\mathrm{S}^{12+}$ beams had required a new (ECR) source and a dedicated RFQ. Pb ions need not only a new Linac but also substantial modifications of the circular accelerators (Fig. 1). Actually about half of the investment went into up-grading the circular machines.

\section{BASIC PHILOSOPHY AND DESIGN OF THE LEAD ION ACCELERATING FACILITY}

If a brand new facility to accelerate $\mathrm{Pb}$ ions to high energies would have had to be constructed, it is clear that the machines to accomplish this task would look drastically different from what has been built at CERN in the context of this project $[5,6]$. To accelerate ions (heavier than protons) has not been CERN's main goal in the recent past. Ions were dealt with by dedicated laboratories like GSI, GANIL, Berkeley and others. Only a minority of nuclear physicists expressed interest in the higher energies the CERN machines were able to provide. Though they could convince the CERN management to deviate some effort towards ions, it was certain that this effort would remain fairly limited. Without external collaboration nothing would have been achieved. From this it is clear that it was necessary to keep the modifications to the existing machines and the construction of new ones to an absolute minimum.

After the oxygen/sulphur acceleration it was obvious that fully stripped ions could be handled by the existing circular machines without too many problems. The problem was rather how to get fully stripped lead ions. There is no source that could provide the minimum intensity, specified by the interested physicists community: $5 \cdot 10^{7}$ per SPS supercycle. For reasonable intensities the charge states or rather the more interesting charge to mass ratio is much lower. The compromise selected consisted of an ECR (electron cyclotron resonance) source capable of producing $80 \mathrm{e} \mu \mathrm{A}$ of $\mathrm{Pb}^{27+}$. This choice (charge to mass ratio of 0.13 ) unfortunately ruled out any further use of the good old Linac1, which had been pushed to 33\% higher fields in order to accelerate oxygen and sulphur ions with a charge to mass ratio of 0.375 . Being obliged to use a new Linac leaves the question of the desired energy open. To pass through the PSB and the PS with $\mathrm{Pb}^{27+}$ would have required up-grading of the vacuum of these machines with large expenses - beyond the scope of this project.

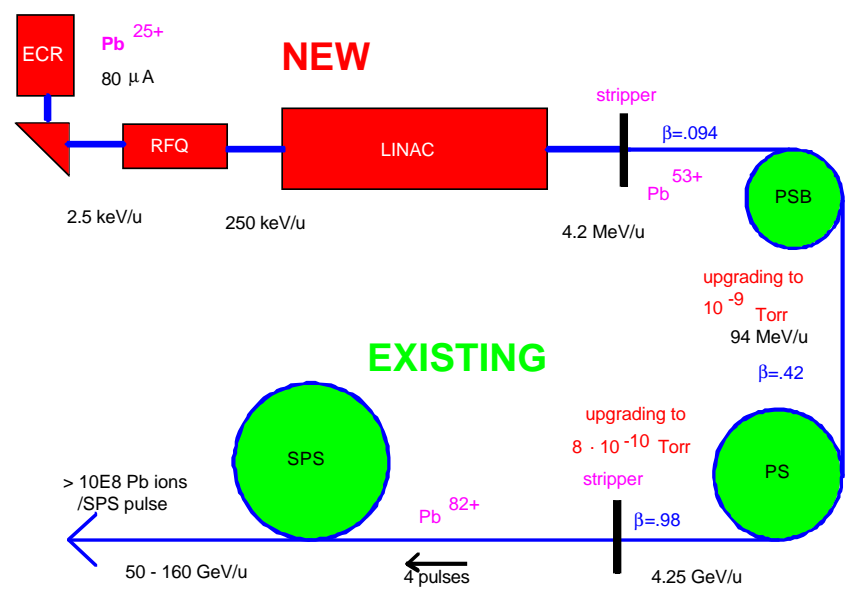

Fig. 1: Layout of the CERN Heavy Ion Accelerating Facility

It was hence necessary to do some intermediate stripping (in spite of the loss in intensity) before the PSB. Inside the circular machine, stripping is impossible because the sudden change of charge to mass ratio can not be accommodated. A higher output energy of the Linac results in a higher charge state after stripping and both make the vacuum requirements less stringent. Unfortunately, there is a complicated injection line to feed the four Booster rings. A substantial up-grading of this line towards higher 
energies - still keeping the $50 \mathrm{MeV}$ proton injection from Linac2 on a pulse to pulse basis - would have meant again high expenditure.

The compromise was to aim at $4.2 \mathrm{MeV} / \mathrm{u}$, which, with a foil stripper, yields $\mathrm{Pb}^{53+}$ as dominant charge state. With these values the magnetic rigidity is just $13 \%$ higher than the one for $50 \mathrm{MeV}$ protons and a very modest up-grading of the injection line elements resulted in the desired performance. Note that up-grading in terms of pulse length for the different pulsed elements in this line was needed in any case to cope with the low velocity of the ions: about a factor 3.5 lower than for the $50 \mathrm{MeV}$ protons.

Basically, existing material has been kept wherever possible, in the circular machines as well as in the beam transfer lines. A new Linac together with its source, however, was unavoidable. We have tried also to standardize, as far as possible within the collaboration, on CERN materials and equipment for ease of maintenance and repairs afterwards. Thanks due to the flexibility of our collaborators, this philosophy has been quite successful.

\section{PRESENT PERFORMANCE}

\section{The Linac}

In spite of the large number of collaborations (all external collaborations were involved in the Linac), construction, installation and running-in worked quite well $[5,6]$. Though several major components were rather late, the last of a series of milestones (injection into the PSB on June 15, 1995) could finally be kept. Performance of the Linac was close to the design values $[6,7,8$ and references therein] as can be seen from Table 1:

\begin{tabular}{|c|c|c|c|c|}
\hline & $\begin{array}{l}\text { horizontal } \\
\text { emittance } \\
\text { [mm mrad] }\end{array}$ & $\begin{array}{c}\text { vertical } \\
\text { emittance } \\
{[\mathrm{mm}} \\
\mathrm{mrad}]\end{array}$ & $\begin{array}{l}\text { energy } \\
\text { spread } \\
{[\mathrm{keV}]}\end{array}$ & $\begin{array}{l}\text { current } \\
{[\mathrm{e} \mu \mathrm{A}]}\end{array}$ \\
\hline design & 1.0 & 1.0 & 2.1 & 20 \\
\hline achieved & 1.2 & 1.2 & 2.5 & 22 \\
\hline
\end{tabular}

Table 1: Linac beam characteristics (at input to PSB)

\section{The Proton Synchrotron Booster (PSB)}

As was well known from the very first discussions and presented already [1], the vacuum pressure is a very critical issue in the Booster synchrotron. A general cleaning and replacement of equipment with a very high outgassing rate had been executed [9] together with the installation of additional pumping capacity ( $\mathrm{Ti}$ sublimation pumps). Unfortunately, several leaks occurred last year causing pressure bumps in two places. The apparent reason has been corrosion due to the decomposition of PVC by the beam induced radiation - after more than 20 years of operation. These leaks have been treated with a plastic sealant which could not yield the ultimate vacuum performance. Though the vacuum has been improved considerably resulting in pressures in the very low $10^{-9}$ Torr range (gauge reading), it was nevertheless important to accelerate as rapidly as possible to overcome the low energy region. Fig. 2 shows the dependence [1] of lifetime versus energy and demonstrates the importance of fast acceleration.

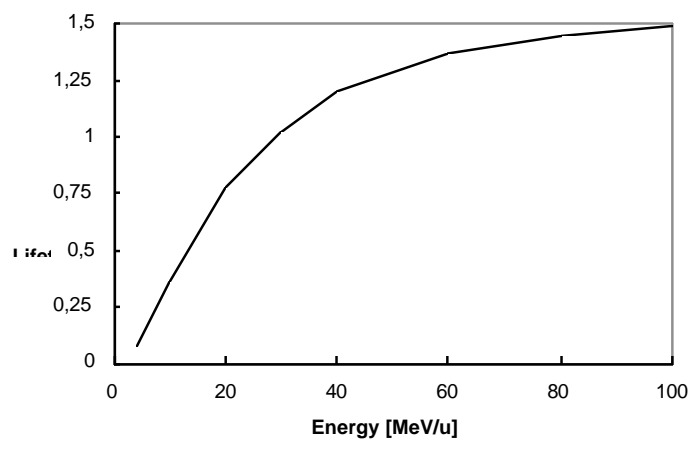

Fig. 2: Lifetime of $\mathrm{Pb}^{53+}$ at $9 \cdot 10^{-9}$ Torr $\left(\mathrm{N}_{2}\right)$ in the PSB as function of energy

Measurements of the beam lifetime when the $\mathrm{Pb}$ ions are injected at constant field showed 30 to $40 \mathrm{~ms}$ instead of the assumed $60 \mathrm{~ms}$ (Fig. 3).

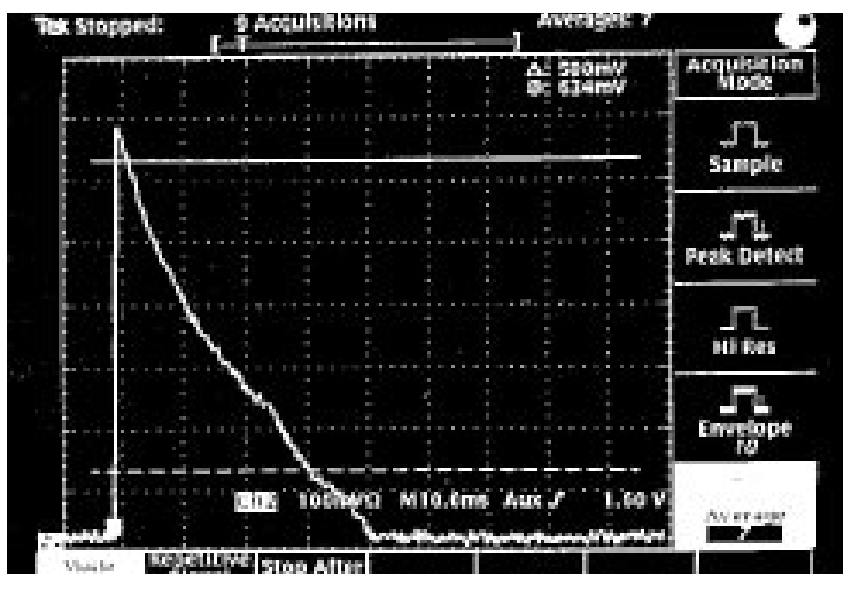

Fig. 3: "Survival" of $\mathrm{Pb}^{53+}$ at $4.2 \mathrm{MeV} / \mathrm{u}$ in the PSB

It must be stressed that vacuum measurements are extremely difficult as what is of interest is the integrated pressure and the residual gas composition around the closed orbit and not the pressure gauge readings at the positions of the gauges. Beam lifetime measurements are actually a much better indication for the real vacuum pressure - if the relevant cross-sections were known precisely.

The vacuum has not been constant, for example a short time after heating the $\mathrm{Ti}$ sublimators, the pressure was lowest and started rising again. Time constants for the pressure rise were between two (in high pressure zones) and ten hours. The resulting intensity variations were between 1.3 and $1.6 \cdot 10^{10}$ charges. As the PSB had not only to work for the ion users but also for other clients, an unexpected effect was noticed that came from high intensity proton beams for ISOLDE (Isotope On Line separator): These beams produced a pressure increase in the PSB reducing the ion transmission in the next cycle. 
Anyhow, by injecting not at a flat field but at the moment where the field is already rising (with $1.8 \mathrm{~T} / \mathrm{s}$ ) together with a fast acceleration, the PSB performance was excellent [10]. Fig. 4 shows oscilloscope traces of the PSB main field (upper trace) and the current in the ring (lower trace - the rising part at the end is not real current but induced noise).

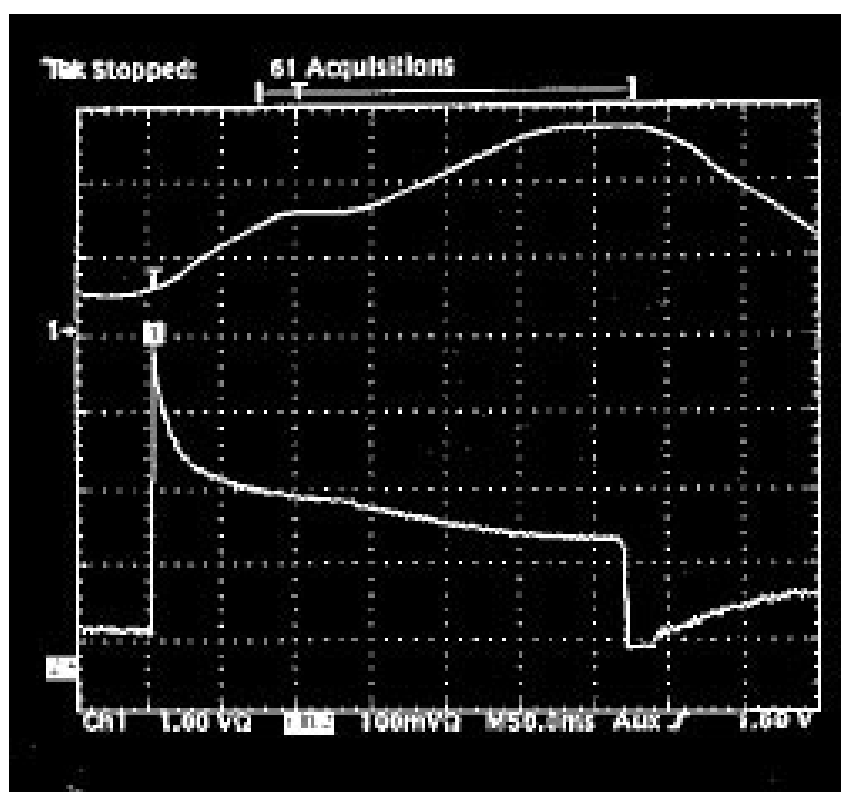

Fig. 4: Field and $\mathrm{Pb}^{53+}$ current in the PSB as function of time

It can be seen that losses are highest at the very beginning (injection, trapping and vacuum) and are lower at later times. The intermediate flat top, where debunching and rebunching occurs, does not contribute much to losses. Actually, due to this fact, another debunching/rebunching cycle was added at the top field before ejection. Originally, it had been foreseen to eject 40 bunches. With the second change of the harmonic number to five in the PSB, 20 bunches are injected into the PS avoiding thus any complicated RF gymnastics in the PS.

\section{The Proton Synchrotron (PS)}

Several improvements were needed for the PS [10] to cope with the low velocity ( $\beta$ still less than $1 / 2$ at injection, revolution time in the PS: $5 \mu \mathrm{s}$ ), the low intensity and the sensitivity to the residual vacuum. To improve the vacuum situation new magnetic septa (bakeable in-situ) were installed together with a large number of $\mathrm{Ti}$ sublimators. The low $\beta$ required lengthened injection kicker pulses and a new digital beam control system uses a radial loop with a sensitive pick-up electrode. Injection takes place at $95.4 \mathrm{MeV} / \mathrm{u}$ (magnetic rigidity corresponding to the usual $1 \mathrm{GeV}$ protons) with 20 bunches from the PSB. Although there would have been some interest to strip before injection into the PS (at this energy to a dominant charge state of $80+$ ), it would have meant a loss in intensity of a factor two and some additional losses due to emittance blow-up. Hence no stripping has been envisaged at this position.

With the choice of the parameters, transition (at $\gamma_{\mathrm{tr}}=6.12$ ) could be avoided with acceleration taking place from $\gamma=1.1$ to 5.56. Being close to transition at ejection means a strong dependence of the momentum with respect to the RF frequency. To lower the energy spread at ejection the RF voltage is reduced.

One supercycle of $19.2 \mathrm{~s}$ is being used with 4 ion batches. As had been anticipated, the leptons (due to their synchrotron radiation) degrade the PS vacuum and hence the ion transmission.

\section{The stripper}

The problems with the stripper behind the PS had been underestimated. The construction of it is fairly complicated because the SPS has not only to work for the ions but also as injector for LEP, i.e. the stripper has to move in and out of the beam on a pulse to pulse basis ("ppm"). To avoid bellows, a magnetic coupling mechanism had been chosen. The physics of the stripper, however, was considered as trivial in view of the very high energy of the ions, although special machine development sessions had been foreseen but were lost due to other priorities. Detailed calculations ( [11] and in particular [12]) were made and showed two essential facts: energy straggling is negligible and the choice of the stripper material ( $\mathrm{Al}, \mathrm{Cu}$ or $\mathrm{Au}$ ) is not important; however, its thickness matters very much in terms of transverse emittance blow-up. For fine tuning, the material maybe of some importance. Experimental verification has been difficult, as it seems we have a large emittance blow-up (or mismatch?) in the transfer line towards the SPS independent of the stripper. In fact this blow-up is there also for $\mathrm{Pb}^{53+}$ and even for similar proton beams. The homogeneity of the stripper is of course a very significant parameter. With the present choice of $0.5 \mathrm{~mm}$ $\mathrm{Al}$, the transverse blow-up is negligible but the stripping efficiency is below $100 \%$, perhaps around $90 \%$.

\section{The Super Proton Synchrotron (SPS)}

The SPS has to deal only with fully stripped ions at high energy and hence does not have any vacuum problems. However, the difficulty of low intensity and even of low velocity remains [13]. The low velocity $(\beta=0.984)$ does not allow normal acceleration with the SPS travelling-wave cavities. Their frequency swing is not large enough: They can cope with only $0.9 \mathrm{MHz}$ (in $200 \mathrm{MHz}$ ); $3.2 \mathrm{MHz}$ is needed for the lead ions. Their short filling time and the fact that the four PS batches do not fill the whole circumference makes it possible to re-phase the cavities for each batch and each revolution [14]. Thus not only acceleration is possible but at injection batches can be trapped while still waiting for the next ones to arrive from the PS.

\section{Instrumentation}

Substantial up-grading of the beam instrumentation has been necessary. Contrary to the situation, for oxygen and 
sulphur ions, it is now possible to perform closed-orbit measurements with pick-up stations (300 units!) equipped with new high sensitivity preamplifiers. New instrumentation was also integrated into the beam transfer lines to the experiments. The number of FISCs (filament scintillation counters) was increased from 40 to 80 . This change (finished in this year's shutdown) became necessary because the normally used SEM grids would spoil the beam quality too much.

\section{Beam performance}

Setting-up of the machine has been hampered by the loss of all "long" MD-sessions due to problems with the $400 \mathrm{kV}$ mains and the vacuum. A further boundary condition was the parallel running of LEP, which uses the SPS as injector. Due to the emittance problem mentioned above there were no ideal conditions for high efficiency injection. In addition the $0.5 \mathrm{~mm}$ stripper does not give the optimum performance in terms of stripping efficiency.

The intensities achieved per SPS super cycle are compared in Table 2 with the estimated [1]values:

\begin{tabular}{|l|c|c|c|}
\hline & energy & estimated & achieved \\
\hline Linac out & $4.2 \mathrm{MeV} / \mathrm{u}$ & $3.7 \cdot 10^{9}$ & $4.2 \cdot 10^{9}$ \\
\hline PSB (accel.) & $94 \mathrm{MeV} / \mathrm{u}$ & $8.9 \cdot 10^{8}$ & $1.2 \cdot 10^{9}$ \\
\hline PS (accel.) & $4.25 \mathrm{GeV} / \mathrm{u}$ & $5.9 \cdot 10^{8}$ & $7.5 \cdot 10^{8}$ \\
\hline SPS (accel.) & $160 \mathrm{GeV} / \mathrm{u}$ & $3.9 \cdot 10^{8}$ & $2.7 \cdot 10^{8}$ \\
\hline
\end{tabular}

Table 2: Intensities in ions per SPS super cycle and energy of the accelerators.

The original request from the heavy ion physics community was $5 \cdot 10^{7}$ ions / supercycle, hence, for the time being, most of our clients are satisfied.

\section{POSSIBLE IMPROVEMENTS}

In spite of these excellent results it is very likely that future experiments will require higher intensities. This is in particular true for the LHC (Large Hadron Collider) where lead ions will be accelerated to a few TeV/u. Various possibilities are open to satisfy prospective clients.

Intensity improvements on the source, which are possible, will reflect proportionally on the final intensities. Additional improvements in the vacuum pressure in the PS and especially in the PSB, both done in the 1995 annual shutdown, will also increase the performance. Study of the emittance blow-up or mismatch in the PS - SPS transfer line is of high priority.

For the LHC several means have been studied $[15,16]$ to achieve the required luminosities. The most promising scheme is a faster $(10 \mathrm{~Hz})$ repetition rate of the Linac and injection into LEAR (Low Energy Antiproton Ring). Accumulation of several pulses and electron cooling would provide for the intensities and emittances needed for the LHC.

A first electron cooling test with $\mathrm{Pb}^{53+}$ ions was performed in LEAR in December 1994 [17]. The test showed, that cooling time constants (1/e) of $50 \mathrm{~ms}$ for the momentum and of $300 \mathrm{~ms}$ for the transverse emittances can already be reached with the present state of the cooler. However the lifetime of the ion beam decreased to values of $2 \mathrm{~s}$ in the presence of an electron beam of $0.4 \mathrm{~A}$. This effect has to be carefully studied in further tests at LEAR and at other cooling rings. The dependence on the charge state of the ion and on the magnetic field of the cooler is of importance in the search of conditions for a lifetime longer than the stacking time of 2 to 3 seconds.

Another possibility, depending on ion source development [18,19], is a high current, short pulse, source (EBIS or Laser source) that could provide the necessary intensity and keep the required low emittance by monoturn injection into the PSB. Work in this field is going on in some labs, e.g. BNL (EBIS) and CERN (Laser source, in collaboration with ITEP and TRINITI).

\section{CONCLUSION AND ACKNOWLEDGMENTS}

It has been demonstrated that proton machines can be efficiently up-graded for operation with ions, and that a large collaboration of several labs from different countries can not only build experiments, but also accelerators, which are supposed to have a longer life and must be integrated into the existing "accelerator environment".

It is a pleasure to acknowledge the substantial help given to this project by our friends from the collaborating institutions. Their enthusiasm was essential for our success. Thanks are of course also due to the CERN people in the different groups of the PS division, but also from the SL, AT, MT, ST and TIS divisions.

Special thanks go to several of my colleagues in PS and SPS for supplying material for this paper.

\section{REFERENCES}

[1] N. Angert, M. P. Bourgarel, E. Brouzet, R. Cappi, D. Dekkers, J. Evans, G. Gelato, H. Haseroth, C. E. Hill, G. Hutter, J. Knott, H. Kugler, A. Lombardi, H. Lustig, E. Malwitz, F. Nitsch, G. Parisi, A. Pisent, U. Raich, U. Ratzinger, L. Riccati, A. Schempp, K. Schindl, H. Schönauer, P. Têtu, H. H. Umstätter, M. van Rooij, D. Warner (Ed.), M. Weiss, CERN Heavy Ion Facility Design Report, CERN 93-01.

[2] R. Billinge, E. Boltezar, D. Boussard, E. Brouzet, R. Cappi, B. de Raad, N. Doble, P. Grafström, H. Haseroth (Ed.), C.E. Hill, K.H. Kissler, J. Knott, T. Linnecar, F. Nitsch, A. Poncet, U. Raich, N. Rasmussen, H. Schönauer, T.R. Sherwood, N. Siegel, U. Tallgren, P. Têtu, D. Warner, M. Weiss, "Concept for a lead-ion accelerating facility at CERN", CERN/PS 88-67 (DL) 1988 and CERN 90-01.

[3] N. Angert, R. Caylor, R.A. Gough, H. Haseroth, C.E. Hill, D. Howard, J. Klabunde, B. Langenbeck, K. Leible, R. MacGill, P. Spädtke, J. Staples, J. Tanabe, P. Têtu, M. Weiss, B.H. Wolf, "Ion acceleration in the CERN 
Linac 1", Lin. Acc. Conf., Stanford , Calif., 1986 (SLACReport-303, Stanford, Calif., 1986), p. 355.

[4] N. Angert, E. Brouzet, R. Garoby, S. Hancock, H. Haseroth, C.E. Hill, K. Schindl, P. Têtu, "Accelerating and separating mixed beams of ions with similar charge to mass ratio in the CERN PS complex", Proc. Europ. Particle Acc. Conf., Rome, 1988, Ed. S. Tazzari (World Scientific, Singapore, 1988), vol. 2, p. 1367.

[5] H. Haseroth, "The CERN Heavy Ion Facility", Proc. of the Fourth European Particle Acc. Conf., EPAC94, London.

[6] D. J. Warner, "The Heavy Ion Linac for the CERN Lead Ion Facility", Proc. of the 1994 International Linac Conf., Tsukuba.

[7] N. Angert, W. Bleuel, H. Gaiser, G. Hutter, E. Malwitz, R. Popescu, M. Rau, U. Ratzinger, Y. Bylinski, H. Haseroth, H. Kugler, R. Scrivens, E. Tanke, D. Warner, "The IH Linac of the CERN Lead Injector", LINAC94, Tsukuba.

[8] M. Crescenti, U. Raich, "A Single Pulse Beam Emittance Measurement for the CERN Heavy Ion Linac", to be published in the Proc. of the Second European Workshop on Beam Diagnostics and Instrumentation for Particle Accelerators, DESY 1995.

[9] M. van Rooij, J-P. Bertuzzi, M. Brouet, A. Burlet, C. Burnside, R. Gavaggio, L. Petty, A. Poncet, "The Vaccum Upgrade of the CERN PS and PS Booster, this conference.

[10] H. Schönauer, F. Blas, P. Bossard, R. Cappi, G. Cyvoct, R. Garoby, G. Gelato, H. Haseroth, E. Jensen, D. Manglunki, K. Metzmacher, F. Pedersen, N. Rasmussen, K. Schindl, G. C. Schneider, M. van Rooij, L. Sermeus, M. Thivent, F. Völker, E. Wildner, "Acceleration of Lead Ions in the CERN PS Booster and the CERN PS", this conference.

[11] R. Cappi, D. Manglunki, B. Vandorpe, "Preliminary Results of $\mathrm{Pb}^{53+}$ Total Stripping at 5.2 GeV/u”, CERN, PS/PA Note 95-01, 1995.

[12] C. Scheidenberger, H. Geissel, H. Mikkelsen, F. Nickel, T. Brohm, H. Folger, H. Irnich, A. Magel, M. F. Mohar, G. Münzenberg, M. Pfützner, E. Roeckl, I. Schall, D. Schardt, K. H. Schmidt, W. Schwab, M. Steiner, Th. Stöhlker, K. Sümmerer, D. J. Vieira, B. Voss, M. Weber, "Direct Observation of Systematic Deviations from the Bethe Stopping Theory for Relativistic Heavy Ions", Phys. Rev. Lett., Vol. 73, 1, 50, 1994.

[13] A. Faugier, X. Altuna, R. Bailey, R. Blanchard, T. Bohl, E. Brouzet, H. Burkhardt, P. Collier, K. Cornelis, G. de Rijk, F. Ferrioli, A. Hilaire, M. Lamont, T. Linnecar, M. Jonker, C. Niquille, G. Roy, H. Schmickler, "The SPS as Accelerator of $\mathrm{Pb}^{82+}$ Ions", this conference.

[14] D. Boussard, T. Bohl, T. Linnecar, U. Wehrle, "Non Integer Harmonic Number Acceleration of Lead Ions in the CERN SPS", this conference.

[15] D. Brandt, E. Brouzet, R. Cappi, J. Gareyte, R. Garoby, H. Haseroth, P. Lefèvre, S. Maury, D. Möhl, F. Pedersen, K. Schindl, T.R. Sherwood, L. Thorndal, D. Warner, "High Intensity Options for the CERN Heavy Ion
Programme", Proc. of the 2nd European Particle Acc. Conf., Nice 1990, vol. 1, p.49.

[16] P. Lefèvre, D Möhl, "Lead Ion Accumulation Scheme for LEAR", Workshop on Beam Cooling and Related Topics, Montreux, Switzerland, 1993

[17] S. Baird, J. Bosser, M. Chanel, J. Duran, R. Giannini, P Lefèvre, R. Ley, R. Maccaferri, S. Maury, I. Meskov, D. Möhl, G. Molinari, F. Motsch, H. Mulder, U. Öftiger, J. Perrier, E. Roux, G. Tranquille, F. Varenne, "First electron Cooling Test with PB53+ Ions", CERN PS/AR/Note 95-6, 1995

[18] H. Haseroth, K. Prelec, "Possible Applications of an EBIS in Preinjectors for Large Heavy Ion Colliders", 6th Intern. Symp. Electron Beam Ion Sources and their Applications, Stockholm, June 20 - 23, 1994.

[19] T. R. Sherwood, "Laser Ion Sources for High Energy Particle Accelerators", Proceedings of the 12th Intern. Conf. on Laser Interaction and Related Plasma Phenomena, Osaka, 1995. 